\title{
Sociodemographic, behavioural and health factors associated with changes in older adults' TV viewing over 2 years
}

\author{
Benjamin Gardner ${ }^{1 *}$, Steve lliffe ${ }^{2}$, Kenneth R Fox ${ }^{3}$, Barbara J Jefferis ${ }^{2,4}$ and Mark Hamer ${ }^{4,5}$
}

\begin{abstract}
Background: Of all age groups, older adults spend the most time watching TV, which is one of the most common sedentary behaviours. Such sedentary activity in older adulthood is thought to risk deterioration of physical and mental functioning, health and wellbeing. Identifying the characteristics of older adults whose TV viewing increases over time may help to target sedentary behaviour reduction interventions to those in most urgent need. Yet, studies of the factors associated with TV viewing have predominantly been cross-sectional. This study used a prospective design to describe changes in TV viewing over a two-year follow-up period, and to model socio-demographic, behavioural and health factors associated with observed changes in viewing time.

Methods: A two-year follow-up of 6,090 male and female older adults (mean age 64.9 4.9 years) was conducted in the English Longitudinal Study of Ageing, a cohort of community dwelling older adults. TV viewing time was self-reported at baseline and at follow-up. The sample was categorised according to baseline TV viewing duration ( $<2 \mathrm{hrs} / \mathrm{d}, 2<4 \mathrm{hrs} / \mathrm{d}, 4<6 \mathrm{hrs} / \mathrm{d}, \geq 6 \mathrm{hrs} / \mathrm{d}$ ), and the observed direction and extent of changes in viewing duration were described for each category. Socio-demographic, behavioural and health variables (socioeconomic status, depressive symptoms, disability, chronic illness, body mass index, physical activity, smoking), as measured at baseline, were entered into regression models as predictors of changes in TV viewing time between baseline and follow-up.

Results: Mean self-reported TV viewing time increased from $5.32 \pm 4.08 \mathrm{hrs} / \mathrm{d}$ at baseline to $5.53 \pm 4.19 \mathrm{hrs} / \mathrm{d}$ at follow-up ( $p<0.001)$. Forty-nine per cent of participants increased their TV viewing ( $23 \%$ of all participants by 60 minutes or more), $41 \%$ decreased their viewing, and 10\% reported no change in viewing duration. Increases in TV viewing at follow-up were associated with lower socioeconomic status, presence of depressive symptoms, higher BMI, physical inactivity, and being a smoker at baseline.
\end{abstract}

Conclusions: Findings call for the development of effective behaviour change interventions to counter increases in inactive TV viewing among older adults, and point to subgroups who may need to be prioritised for such interventions.

Keywords: Older adults, Sedentary behaviour, TV viewing, Screen time, Prospective

\section{Background}

Sedentary behaviour - i.e., low energy-expenditure activity undertaken in a sitting or reclining position [1] - is associated with adverse physical and mental health outcomes [2-4]. Even among the physically active, time spent sedentary is associated with higher waist circumference, blood pressure, and 2-hour plasma glucose $[5,6]$.

\footnotetext{
*Correspondence: b.gardner@ucl.ac.uk

${ }^{1}$ Health Behaviour Research Centre, Department of Epidemiology and Public Health, University College London, London, UK

Full list of author information is available at the end of the article
}

Sedentary behaviour thus appears to have deleterious health effects even where physical activity recommendations are met $[7,8]$, and so sitting time is now recognised as a health risk factor independent of physical activity [9]. Physical activity guidelines are increasingly incorporating recommendations to limit sedentary time [10].

Older adults are more likely than other age groups to be sedentary $[11,12]$. TV viewing, one of the most prevalent leisure-time sedentary activities [13], is particularly common in older adults. It is estimated that adults typically spend $60-70 \%$ of waking time in sedentary activities $[14,15]$, 
and UK adults aged 65 or above spend an average 4 hours a day watching TV [16]. Given the sedentary nature of typical TV viewing episodes, studies have linked viewing time in older adulthood to poorer physical health, and greater depression, anxiety, and cognitive decline [17-21]. Substituting sedentary TV viewing time for non-sedentary activities has the potential to yield significant population-level health impacts among the elderly.

Cross-sectional comparisons across age groups suggest that as people get older, they tend to watch more TV and become less active [12,16]. Such increases in sedentary behaviour and declines in physical activity are thought to risk deterioration in physical and cognitive functioning, health, and wellbeing [18-20,22,23]. Yet, few studies have described changes in TV viewing within a cohort over time. Of these, most have focused on the retirement window, finding that TV viewing time significantly increases following the transition to retirement [24]. Little evidence is available on the stability of TV viewing patterns in older adulthood in the absence of, or when controlling for, context change. Natural variation in viewing time should be accounted for when developing and estimating the effectiveness of interventions to reduce sedentary TV viewing time. Additionally, modelling the sociodemographic, behavioural and health factors associated with increased $\mathrm{TV}$ viewing may aid identification of subgroups of older adults who are most at risk of losses of function and health, and so in most urgent need of intervention [25]. Several observational studies have demonstrated associations between lifestyle factors and TV viewing; for example, individuals who are physically inactive, smokers, and people with obesity tend to spend more time watching TV [26]. However, it is unclear whether factors associated with TV viewing are also associated with changes in TV viewing.

This study drew on prospective data from a large, nationally representative cohort of UK older adults, to document changes in TV viewing duration over a twoyear follow-up, and to identify socio-demographic, behavioural and health factors associated with changes in viewing time.

\section{Methods}

\section{Study sample and procedures}

Data were obtained from the English Longitudinal Study of Ageing (ELSA), an ongoing cohort study that contains a nationally representative sample of the English population living in households [27]. The ELSA cohort consists of men and women born on or before 29 February 1952, using multistage stratified probability sampling with postcode sectors selected at the first stage and household addresses selected at the second stage. The ELSA dataset is publicly available for research purposes, and to preserve participant anonymity, the organisation that collected data removed postcode and all other geographical identifiers from the dataset prior to release, thus precluding any analyses of potential spatial clustering effects. Participants gave full informed written consent to participate in the study and ethical approval was obtained from the London Multi-centre Research Ethics Committee.

For the purposes of the present analyses, data collected at wave 4 (2008-09, and wave 5 (2010-11) were used as these were the only waves at which TV viewing data were gathered. A total of 10,603 participants attended wave 4 (baseline), of whom 3,476 (32.8\%) were excluded due to incomplete baseline data on TV viewing time, age or sex. Of the remaining 7,127 (62.7\%) participants, 1,037 (14.5\%) were lost to follow-up at wave 5 (follow-up), leaving a final analytic sample of 6,090 participants. Compared to those in the final sample, baseline participants subsequently excluded for any reason were older $(64.9 \pm 8.9$ vs $65.5 \pm 12.0 ; \mathrm{p}=.005)$, more likely to be smokers $(12.1 \%$ vs $17.7 \%$; $p<.001)$, less physically active (proportion doing no moderate or vigorous activity on a weekly basis: $17.8 \%$ vs $31.6 \%$; p <.001), reported more depressive symptoms (11.7\% vs 19.2; $\mathrm{p}<.001$ ), of lower SES (proportion in routine or manual occupations: $36.7 \%$ vs $41.3 \% ; \mathrm{p}<.001$ ), and more likely to have chronic illness $(52.0 \%$ vs $56.6 \%$; $\mathrm{p}<.001)$ or disability $(20.9 \%$ vs $32.1 \%$; $<.001)$. There were no differences in baseline TV viewing $(\mathrm{p}=.22)$, gender $(\mathrm{p}=.054)$, or obesity $(\mathrm{p}=.77)$.

\section{Measures}

TV viewing

Data on TV viewing was collected at baseline and follow-up. Participants were asked to indicate, in whole hours, "How many hours of television do you watch on an ordinary day or evening, that is, Monday to Friday?" and "How many hours of television do you normally watch in total over the weekend, that is, Saturday and Sunday?" Average daily time spent watching TV was calculated as $\{(($ weekday TV time $\times 5)+($ weekend TV time) $) / 7\}$, so generating a mean score expressed in decimal hours. For descriptive purposes, average daily TV viewing data were classified into four categories $(<2 \mathrm{hrs} / \mathrm{d}$, $2<4 \mathrm{hrs} / \mathrm{d}, 4<6 \mathrm{hrs} / \mathrm{d}, \geq 6 \mathrm{hrs} / \mathrm{d}$ ). The population of the $\mathrm{TV}$ viewing duration categories at baseline and follow-up are described in Additional file 1: Table S1. Changes in $\mathrm{TV}$ viewing were expressed in minutes, following conversion of mean differences between baseline and follow-up from decimal hours to minutes.

\section{Independent variables}

Various demographic and health-related questions were administered by trained interviewers. Single-items were used unless otherwise specified. Age and sex were self- 
reported. Retirement status was obtained via a question about current working situation (retired, semi-retired, employed, self-employed, unemployed, permanent sick or disabled, looking after home or family, other). Participants who chose the first option were treated as retired, and all others as non-retired. Cigarette smoking was recorded (current, previous or non-smoker). Participants were asked how often they took part in vigorous, moderate- and low-intensity physical activity. Before answering, participants were shown prompt cards to help them interpret different PA intensities. Examples of moderate intensity activity included gardening, cleaning the car, walking at moderate pace, dancing, and floor or stretching exercises; vigorous intensity included running/jogging, swimming, cycling, aerobics/gym workout, tennis, and digging with a spade. Response options were: more than once a week, once a week, one to three times a month and hardly ever/never. Physical activity was further categorized into a binary variable based on reporting moderate or vigorous activity at least once a week (yes/no [28]). Self-reported chronic illness was recorded (yes/no). Depressive symptoms were assessed using the 8-item Centre of Epidemiological Studies Depression (CES-D) scale, which has been validated for use in older adults [29,30]. Socioeconomic status (SES) was assessed based on the last/most recent occupation and categorized into three groups (managerial/professional; intermediate; routine/manual occupations); a minority of responses that could not be reliably fitted into these categories were classified as 'other'.

Disability was based on participants' responses to questions on perceived difficulties in 6 basic activities (e.g., difficulty dressing, including putting on shoes and socks) and 7 instrumental activities of daily living (e.g., difficulty preparing a hot meal $[31,32]$ ). Participants with difficulties in one or more activities were considered to have some degree of disability.

Nurses collected anthropometric data (weight, height). Participants' body weight was measured using Tanita electronic scales without shoes and in light clothing, and height was measured using a Stadiometer with the Frankfort plane in the horizontal position. Body mass index (BMI) was calculated using the standard formulae (weight [kilograms]/height [metres] squared).

\section{Statistical analyses}

Differences in the socio-demographic, behavioural and health profile of participants in each baseline TV viewing hours category $(2 \mathrm{hrs} / \mathrm{d}, 2<4 \mathrm{hrs} / \mathrm{d}, 4<6 \mathrm{hrs} / \mathrm{d}, \geq 6 \mathrm{hrs} /$ d) were examined using ANOVA for continuous and Pearson's $X^{2}$ for non-continuous variables.

For illustrative purposes, the direction and magnitude of changes in viewing patterns were described for participants in each baseline TV hours category. Differences of $\geq 1$ min in mean TV viewing duration between baseline and follow-up were treated as a change in viewing time, and differences of $<1 \mathrm{~min}$ as no change. Paired samples t-tests were run to examine changes in average $\mathrm{TV}$ viewing times (continuous data) between baseline and follow-up.

Longitudinal associations between independent variables at baseline and changes in TV viewing hours between baseline and follow-up were examined using linear regression. Two incremental models were fitted: Model 1 adjusted for sex, age and baseline TV viewing, and Model 2 additionally adjusted mutually for all variables. A corresponding supplementary analysis was run to model absolute TV viewing scores at follow-up, with no adjustment for baseline TV viewing. Comparison of coefficients from this analysis, reported in Additional file 1: Table S2, with those reported in the main analysis below permits exploration of whether factors associated with TV viewing hours at follow-up retained predictive value when modeled as predictors of changes in TV viewing hours [33]. Variations of these models were also run including retirement status as a covariate, but retirement did not predict TV viewing change, or absolute TV viewing, so was not considered further. A sensitivity analysis confirmed that similar results from regression models for the full sample were found when selecting only fully retired participants $(\mathrm{N}=3,203 ; 52.6 \%$ of sample); these data are reported in Additional file 1: Table S3. All analyses were conducted using SPSS v21 with statistical significance set at $\mathrm{p}<0.05$.

\section{Results}

\section{Sample characteristics}

Baseline sample characteristics are shown in Table 1 . Participants in the highest TV viewing categories tended to have lower SES, report more depressive symptoms, smoke, be physically inactive, obese, and report chronic illness and disability.

\section{Observed changes in TV viewing}

Weekday TV viewing time increased from $5.83 \pm(\mathrm{SD})$ $5.26 \mathrm{hrs} / \mathrm{d}$ at baseline to $6.07 \pm 5.37 \mathrm{hrs} / \mathrm{d}$ at follow up $(\mathrm{p}=0.002)$, and weekend TV time increased from $4.05 \pm$ $2.48 \mathrm{hrs} / \mathrm{d}$ to $4.17 \pm 2.62 \mathrm{hrs} / \mathrm{d}$ at follow-up $(\mathrm{p}<0.001)$. Average daily TV viewing increased from $5.32 \pm$ $4.08 \mathrm{hrs} / \mathrm{d}$ at baseline to $5.53 \pm 4.19 \mathrm{hrs} / \mathrm{d}$ at follow up $(\mathrm{p}<0.001)$. The overall change in daily viewing reflected an average increase of $12 \mathrm{~min} / \mathrm{d}$ although there was large variation $(\mathrm{SD}=4.5 \mathrm{hrs} / \mathrm{d})$. At both timepoints, participants most typically watched 2-4 hours of TV per day (baseline: $\mathrm{N}=2,100,34.5 \%$; follow-up: $\mathrm{N}=2,075,34.2 \%$ ).

While a minority of participants $(\mathrm{N}=617 ; 10.1 \%)$ showed no change in TV viewing duration over the two waves (Table 2), 3,001 (49.3\%) reported an increase. Of 
those increasing their viewing, 1,593 (53.1\% of increasers; $26.2 \%$ of total sample) watched more than 60 minutes additional TV per day. Decreases in TV viewing were reported by 2,472 participants (40.6\%).

Of those watching $<2 \mathrm{hrs} / \mathrm{d}$ at baseline $(\mathrm{N}=616)$, twothirds $(\mathrm{N}=418 ; 67.8 \%)$ increased their average viewing time, most commonly by $1<60$ mins $(\mathrm{N}=258 ; 41.9 \%)$, and viewing time decreased for 88 participants (14.3\%). Of 2,100 participants watching $2<4 \mathrm{hrs} / \mathrm{d}$ at baseline, $1,275(60.7 \%)$ increased their viewing time, most typically by $1<60 \mathrm{mins}(\mathrm{N}=658 ; 31.3 \%)$, and 567 (27.0\%) decreased their viewing time. Around half of participants watching $4<6 \mathrm{hrs} / \mathrm{d}$ at baseline $(\mathrm{N}=1,663)$ increased their viewing time $(\mathrm{N}=806 ; 48.5 \%)$, most of whom increased by $>60$ mins $(\mathrm{N}=445 ; 26.8 \%)$, though 688 participants (41.4\%) reduced viewing time. Of the 1,711 participants watching $\geq 6 \mathrm{hrs} / \mathrm{d}$ at baseline, 502 (29.3\%) reported increases in viewing time, but the majority $(\mathrm{N}=1,129 ; 66.0 \%)$ decreased their viewing time.

\section{Factors associated with changes in TV viewing}

In models adjusting for age, sex, and baseline TV viewing, increases in TV viewing time at follow-up were associated with lower SES, depressive symptoms, disability, chronic illness, higher BMI, physical inactivity and smoking (see Table 3).

When also mutually controlling for all variables as covariates, associations for SES, depression, BMI, physical activity, and smoking status remained. Hours of TV viewing increased more markedly among participants in intermediate $(\mathrm{B}=0.36$ [95\% CI: $0.11,0.60])$ or manual/ routine social occupational classes $(B=1.12[0.89,1.36]$; $\mathrm{p}<.001)$ compared to those of managerial/professional status. Participants with depressive symptoms increased their TV viewing more than did those without $(B=0.43$ $[0.12,0.74], \mathrm{p}=.007)$. TV viewing increased more among overweight or obese participants (BMI $\geq 25<30 \mathrm{~B}=0.43$ $[0.19,0.66] ; \mathrm{BMI} \geq 30 \mathrm{~B}=0.82[0.56,1.08] ; \mathrm{p}<.001)$ than among those of normal weight or underweight, and decreased over time in physically active participants (relative to inactivity, moderate $\mathrm{B}=-0.65[-0.92,-0.37]$; vigorous $\mathrm{B}=-0.57[-0.78,-0.26] ; \mathrm{p}<.001)$. Relative to never-smokers, current smokers reported greater increases in TV viewing $(B=0.71[0.39,1.03] ; \mathrm{p}<.001)$, but no association was found among ex-smokers $(\mathrm{B}=$ $0.02[-0.19,0.23])$. There were no associations of disability $(\mathrm{p}=.06)$ or chronic illness $(\mathrm{p}=.73)$ with changes in $\mathrm{TV}$ viewing.

\section{Discussion}

This prospective study of a large and nationally representative cohort of older adults in England sought to describe changes in participants' TV viewing time over a 2-year follow-up period, and model socio-demographic, behavioural and health factors associated with increases in TV viewing. Results showed that participants watched an average of over 5 hours of TV at baseline, and mean viewing time across the whole cohort increased slightly but significantly over time. While $41 \%$ of participants decreased their viewing over the two waves, half of participants increased their viewing, with a quarter of the sample watching at least one more hour of TV daily at follow-up. Increases in TV viewing were associated with lower socioeconomic status, depressive symptoms, higher BMI, lower levels of physical activity, and being a smoker.

To our knowledge, our study is one of the first to use prospective data to describe variation in TV viewing over time. In addition to observing mean increases in viewing time, we also investigated patterns of change according to baseline viewing duration. These showed a general tendency towards increased viewing among participants

Table 1 Baseline characteristics of the sample, organised by baseline mean TV viewing time

\begin{tabular}{|c|c|c|c|c|c|c|}
\hline & $\begin{array}{l}\text { Total sample } \\
(n=6090)\end{array}$ & $\begin{array}{l}<2 \mathrm{hrs} / \mathrm{d} \\
(\mathrm{n}=622)\end{array}$ & $\begin{array}{l}2<4 \mathrm{hrs} / \mathrm{d} \\
(\mathrm{n}=2077)\end{array}$ & $\begin{array}{l}4<6 \mathrm{hrs} / \mathrm{d} \\
(\mathrm{n}=1672)\end{array}$ & $\begin{array}{l}\geq 6 \mathrm{hrs} / \mathrm{d} \\
(\mathrm{n}=1718)\end{array}$ & Test for difference \\
\hline Age (mean [SD] years) & $64.9 \pm 8.9$ & $63.6 \pm 8.9$ & $64.4 \pm 8.9$ & $65.5 \pm 9.0$ & $65.3 \pm 8.9$ & $F=10.12^{* * *}$ \\
\hline Men & 45.2 & 53.4 & 47.7 & 42.4 & 41.4 & $x^{2}=37.58^{* * *}$ \\
\hline Lowest social status $^{\ddagger}$ & 36.7 & 17.8 & 26.2 & 39.8 & 54.0 & $x^{2}=510.22^{* * *}$ \\
\hline Depressive symptoms & 11.7 & 9.5 & 8.1 & 12.1 & 16.4 & $x^{2}=68.55^{* * *}$ \\
\hline Disability & 20.9 & 14.6 & 15.5 & 21.5 & 29.6 & $x^{2}=134.62^{* * *}$ \\
\hline Chronic illness & 52.0 & 45.0 & 48.3 & 54.2 & 57.1 & $x^{2}=44.76^{* * *}$ \\
\hline Obese $\left(\mathrm{BMI} \geq 30 \mathrm{~kg} / \mathrm{m}^{2}\right)$ & 31.2 & 18.3 & 26.4 & 34.0 & 39.2 & $x^{2}=169.58^{* * *}$ \\
\hline Physically inactive ${ }^{\dagger}$ & 17.8 & 9.0 & 13.3 & 19.9 & 25.0 & $x^{2}=216.26^{* * *}$ \\
\hline Current smokers & 12.1 & 6.0 & 10.2 & 11.7 & 18.0 & $x^{2}=88.88^{* * *}$ \\
\hline
\end{tabular}

Data presented are percentages unless otherwise stated.

${ }^{\dagger}$ Defined as no moderate or vigorous activity on a weekly basis.

${ }^{\ddagger}$ Defined as routine/manual occupations.

*** $\mathrm{p}<.001$. 
Table 2 Changes in mean TV viewing time between baseline and 2-year follow-up $(N=6,090)$

\begin{tabular}{|c|c|c|c|c|c|c|}
\hline & & \multicolumn{4}{|c|}{ Change in TV viewing between baseline and follow-up $\mathrm{n}(\%)$} & \multirow{2}{*}{$\begin{array}{l}\text { TOTAL } \\
\text { n (\%) }\end{array}$} \\
\hline & & $\begin{array}{l}\text { Decrease, } \\
\geq 1 \mathrm{~min}\end{array}$ & $\begin{array}{l}\text { No change }(\geq 0<1 \mathrm{~min} \\
\text { difference) }\end{array}$ & $\begin{array}{l}\text { Increase, }>1 \\
<60 \text { mins }\end{array}$ & $\begin{array}{l}\text { Increase, } \\
\geq 60 \mathrm{mins}\end{array}$ & \\
\hline \multirow[t]{4}{*}{ Baseline viewing duration $\mathrm{n}(\%)$} & $<2 \mathrm{hr} / \mathrm{d}$ & $88(1.4 \%)$ & $110(1.8 \%)$ & $258(4.2 \%)$ & $160(2.6 \%)$ & $616(10.2 \%)$ \\
\hline & $2<4 \mathrm{hr} / \mathrm{d}$ & $567(9.3 \%)$ & $258(4.2 \%)$ & $658(10.8 \%)$ & $617(10.1 \%)$ & $2100(34.5 \%)$ \\
\hline & $4<6 \mathrm{hr} / \mathrm{d}$ & $688(11.3 \%)$ & $169(2.8 \%)$ & $361(5.9 \%)$ & $445(7.3 \%)$ & $1663(27.4 \%)$ \\
\hline & $\geq 6 \mathrm{hr} / \mathrm{d}$ & $1129(18.5 \%)$ & $80(1.3 \%)$ & $131(2.2 \%)$ & $371(6.1 \%)$ & $1711(28.1 \%)$ \\
\hline TOTAL n (\%) & & $2472(40.6 \%)$ & $617(10.1 \%)$ & $1408(23.1 \%)$ & $1593(26.2 \%)$ & $6090(100 \%)$ \\
\hline
\end{tabular}

Percentages are of total sample.

viewing fewer than 6 hours of TV per day at baseline. While the majority of those watching 6 or more hours per day at baseline reported decreased viewing time at followup, $29 \%$ of this group increased their viewing time by at least one hour. Previous research has suggested that the transition to retirement is associated with increases in TV viewing [24], but we found that retirement status did not predict change in viewing duration. Additionally, similar patterns of results were observed among a subsample of participants who were fully retired at baseline, though depression and smoking predicted viewing change among the full sample but not among the retired. Our findings thus testify to the potential for, and magnitude of, naturally occurring increases in TV viewing among older adults over time, even where accounting for the retirement transition.

Our data support previous studies by demonstrating associations between TV viewing and behavioural and psychosocial variables [26]. For example, a large Belgian cross-sectional sample found higher levels of TV viewing among functionally limited, less educated, widowed, and (semi-)urban dwelling older adults [34]. In a community sample of older Japanese adults, TV time was associated with not being in full-time employment, lower educational attainment, increased weight, living in regional areas and low moderate-to-vigorous physical activity [35]. Yet, factors associated with variation in static TV viewing scores need not be associated with changes in TV viewing over time; indeed, though our supplementary analysis showed that most predictors of TV viewing time also predicted changes in viewing time, chronic illness was associated with greater $\mathrm{TV}$ viewing time at follow-up but not increases in viewing time between waves. Our results showed that older adults with lower SES, depression, overweight and obese, physical inactivity, and smokers were more likely to increase their TV viewing. These subgroups may therefore require especial attention, with a particular focus on cardiovascular and respiratory disorders and mental health problems, when developing sedentary behaviour reduction interventions.

Our findings call for the development of effective behaviour change interventions to reduce sedentary behaviour among older adults. That more physically active participants tended to decrease their TV viewing time over the two waves concurs with previous research showing that engagement in physical activity can reduce time spent in sedentary activity $[12,36]$. Sedentary behaviour change interventions might most usefully seek to displace TV viewing minutes with physical activities. Calls have been made for interventions to encourage older adults to get 'out and about' as a means of displacing sedentary home-based activities such as TV viewing [37]. Yet, seasonal changes, and a perceived lack of safety and security in the local neighbourhood, can limit the effectiveness of non-home-based interventions among the elderly [38]. TV viewing is often driven by enjoyment of TV [39], which may constrain the acceptability of interventions to replace TV viewing with alternative, non-sedentary activities. Given growing evidence of the positive health impacts of minimal-intensity physical activity relative to sedentary behaviour [40-42], it may be feasible and beneficial to health to incorporate light-intensity physical activities into TV viewing patterns. Several potentially low-intensity activities have been proposed for insertion into otherwise sedentary TV viewing periods so as to promote physical activity and reduce sitting time, such as marching on the spot during commercial breaks [43], doing chores [44], operating a foot pedal device [45], or merely standing up, as a balance activity [46]. Frequent performance of such activities has the potential to maintain the muscle power, balance and confidence required to stay physically active in older adulthood [47]. Additionally, behavioural psychology suggests that adding activity into stable TV viewing routines would be particularly conducive to the formation of physical activity habits: consistent repetition of physical activities while watching TV should lead, through associative learning, to the activities becoming automatically activated with minimal mental effort when watching TV $[48,49]$. In this way, physical activity should become an ingrained part of the TV viewing routine [49].

Limitations of this study should be acknowledged. First, the self-report TV viewing measure used has not been 
Table 3 Socio-demographic, behavioural and health factors associated with changes in mean TV viewing time (in hours) between baseline and 2-year follow-up $(N=6,090)$

\begin{tabular}{|c|c|c|c|}
\hline Variable & $\mathrm{N}$ & Model 1 B $(95 \% \mathrm{Cl})$ & Model 2 B $(95 \% \mathrm{Cl})$ \\
\hline \multicolumn{4}{|l|}{ Socioeconomic status* } \\
\hline Managerial/ professional & 2226 & Reference & Reference \\
\hline Intermediate & 1580 & $0.41(0.16,0.66)$ & $0.36(0.11,0.60)$ \\
\hline Manual/routine & 2236 & $1.31(1.08,1.54)$ & $1.12(0.89,1.36)$ \\
\hline Other & 48 & - & - \\
\hline p-trend & & $<0.001$ & $<0.001$ \\
\hline \multicolumn{4}{|l|}{ Depression (CES-D $\geq 4)$} \\
\hline No & 5378 & Reference & Reference \\
\hline Yes & 712 & $0.81(0.51,1.11)$ & $0.43(0.12,0.74)$ \\
\hline p-trend & & $<0.001$ & 0.007 \\
\hline \multicolumn{4}{|l|}{ Disability } \\
\hline No & 4817 & Reference & Reference \\
\hline Yes & 1273 & $0.69(0.45,0.94)$ & $0.25(-0.01,0.52)$ \\
\hline p-trend & & $<0.001$ & 0.06 \\
\hline \multicolumn{4}{|l|}{ Chronic illness } \\
\hline No & 2924 & Reference & Reference \\
\hline Yes & 3166 & $0.27(0.08,0.46)$ & $-0.04(-0.24,0.17)$ \\
\hline p-trend & & 0.007 & 0.73 \\
\hline \multicolumn{4}{|l|}{ Body mass index } \\
\hline $15-25$ & 1631 & Reference & Reference \\
\hline$\geq 25<30$ & 2559 & $0.37(0.13,0.61)$ & $0.43(0.19,0.66)$ \\
\hline$\geq 30$ & 1900 & $0.91(0.65,1.16)$ & $0.82(0.56,1.08)$ \\
\hline p-trend & & $<0.001$ & $<0.001$ \\
\hline \multicolumn{4}{|l|}{ Physical activity } \\
\hline Inactive & 1085 & Reference & Reference \\
\hline Moderate & 3017 & $-0.95(-1.22,-0.68)$ & $-0.65(-0.92,-0.37)$ \\
\hline Vigorous & 1988 & $-1.07(-1.36,-.077)$ & $-0.57(-0.78,-0.26)$ \\
\hline p-trend & & $<0.001$ & $<0.001$ \\
\hline \multicolumn{4}{|l|}{ Smoking } \\
\hline Never & 2503 & Reference & Reference \\
\hline Ex-smoker & 2849 & $0.09(-0.12,0.30)$ & $0.02(-0.19,0.23)$ \\
\hline Current & 738 & $0.93(0.61,1.25)$ & $0.71(0.39,1.03)$ \\
\hline p-trend & & $<0.001$ & $<0.001$ \\
\hline
\end{tabular}

Model 1 adjusted for age, sex and baseline TV viewing. Model 2 adjusted for age, sex, baseline TV viewing and mutually for all variables presented. B (95\% Confidence Interval) coefficients reflect increases in hours/day of TV viewing between baseline and follow-up. ${ }^{*}$ Coefficients are not reported for the 'other' socioeconomic status category due to small sample size and heterogeneity of employment statuses captured by this category. All available data were however entered into the regression model, in that coefficients for other socioeconomic status categories were calculated using dummy variables that contrasted the focal category with all three other categories.

validated. However, many objective accelerometry devices cannot reliably differentiate sitting from other forms of light ambulatory movement, precluding true validation of selfreported sedentary behaviour measures. In the absence of such data, it is notable that the TV measure used in the present dataset has demonstrated convergent validity with various psychosocial, physical and biochemical risk factors hypothesised to be linked with sedentary behaviour
$[18,19,50]$. Second, given the paucity of data on changes in TV viewing duration over time, it is unclear to what extent TV viewing patterns that we have reported are likely to replicate to other samples and settings. Participants reported watching $\mathrm{TV}$ for an average of 4.7 hours per day at baseline and 4.9 at follow-up. This exceeds the average 4 daily hours of TV time observed among older adults in a 2005 UK survey [16], and the 3.0-3.5 daily 
hours observed in UK EPIC-Norfolk data [51]. Levels of sedentary behaviour may differ considerably both across and within nations [11], making it difficult to estimate the generalisability of our data. Relatedly, our analytic sample was healthier and more active than those who were lost to follow-up. Inactive people must be engaged in research for findings to have external validity. Third, all measures were self-reported, and so actual TV viewing time may have been underestimated. In addition, participants may have reported the amount of time the TV was turned on but not necessarily for how long they watched it. Population-based data should ideally employ both self-report and objective measures for verification purposes [52]. It is also unclear whether TV viewing self-reports were consistently accurate over time. Some of the observed variation in TV viewing duration may be attributable to a lack of measurement stability, and it is not possible to isolate true changes in TV time from method error due to inconsistent reporting. More data is needed to evaluate the reliability, replicability and generalisability of our findings to other samples. Fourth, we focused on TV viewing duration, but not the times at which TV viewing occurred. It is unclear whether TV viewing minutes were mostly accrued in prolonged bouts of sitting, or are dispersed over multiple shorter viewing periods throughout the day. Complementing reports of total TV time with accelerometry, so as to obtain timestamped data on when TV viewing most typically occurs, could aid the development of time-appropriate sedentary reduction intervention strategies [12].

\section{Conclusions}

Half of all participants in this large cohort study of older adults increased the time they spent watching TV over a two-year time period. These results are important in documenting natural variation in TV viewing time within a cohort over time, in the absence of intervention. Individuals with lower SES, depressive symptoms, higher BMI, physical inactivity, and smokers exhibited greater increases in TV viewing time. These subgroups represent priority targets for interventions to reduce sedentary behaviour among older adults.

\section{Additional file}

\section{Additional file 1: Table S1. Changes in TV viewing duration}

categories between baseline and 2-year follow-up $(n=6,090)$. Table S2

Socio-demographic, behavioural and health factors associated with TV viewing time (in hours) at 2-year follow-up (no adjustment for baseline TV viewing; $n=6,090)$. Table S3. Socio-demographic, behavioural and health factors associated with changes in TV viewing time (in hours) between baseline and 2-year follow-up in retired participants $(n=3,203)$.

\section{Abbreviations}

BMI: Body mass index; Cl: Confidence interval; CES-D: Centre of Epidemiological Studies Depression scale; ELSA: English Longitudinal Study of Ageing;
SD: Standard deviation; SES: Socioeconomic status; TV: Television; UK: United Kingdom.

\section{Competing interests}

All authors declare that they have no competing interests.

\section{Authors' contributions}

$\mathrm{MH}$ and $\mathrm{BG}$ jointly conceived the original study idea, which was subsequently refined in discussions with $\mathrm{BJ}, \mathrm{KF}$ and $\mathrm{SI}$. MH analysed the data. BG drafted the manuscript. All authors edited the manuscript, and read and approved the final manuscript.

\section{Authors' information}

BJJ is funded by an NIHR Post-Doctoral Fellowship (2010-03-023). MH is supported by the British Heart Foundation (RE/10/005/28296).

\section{Acknowledgements}

The project was supported by a grant from the National Prevention Research Initiative (MR/J000396/1; see http://www.mrc.ac.uk/research/initiatives/ national-prevention-research-initiative-npri/). The NPRI Funding Partners relevant to this award are: Alzheimer's Research Trust; Alzheimer's Society; British Heart Foundation; Cancer Research UK; Chief Scientist Office, Scottish Government Health Directorate; Department of Health; Diabetes UK; Economic and Social Research Council; Health and Social Care Research and Development Division of the Public Health Agency (HSC R\&D Division); Medical Research Council; The Stroke Association; Wellcome Trust; Welsh Assembly Government; and World Cancer Research Fund. Data were made available through the UK Data Archive. The English Longitudinal Study of Ageing (ELSA) was developed by a team of researchers based at University College London, the Institute of Fiscal Studies and the National Centre for Social Research. The core funding is provided by the National Institute on Aging in the United States (grants 2RO1AG7644$01 \mathrm{~A} 1$ and 2RO1AG017644) and a consortium of UK government departments coordinated by the Office for National Statistics. The funders had no role in the study design; in the collection, analysis and interpretation of data; in writing of the report; or in the decision to submit the paper for publication. The developers and funders of ELSA and the Archive do not bear any responsibility for the analyses or interpretations presented here.

\section{Author details}

${ }^{1}$ Health Behaviour Research Centre, Department of Epidemiology and Public Health, University College London, London, UK. ${ }^{2}$ Research Department of Primary Care \& Population Health, University College London, London, UK. ${ }^{3}$ Centre for Exercise, Nutrition and Health Sciences, University of Bristol, Bristol, UK. ${ }^{4}$ Population Health Domain Physical Activity Research Group, University College London, London, UK. ${ }^{5}$ Department of Epidemiology and Public Health, University College London, London, UK.

Received: 30 January 2014 Accepted: 21 July 2014

Published: 15 August 2014

\section{References}

1. SBRN: Standardized use of the terms "sedentary" and "sedentary behaviours". Appl Physiol Nutr Metab 2012, 37:540-542.

2. Hamilton MT, Healy GN, Dunstan DW, Zderic TW, Owen N: Too little exercise and too much sitting: Inactivity physiology and the need for new recommendations on sedentary behavior. Curr Cardiovasc Risk Rep 2008, 2:292-298

3. Owen N, Sugiyama T, Eakin EE, Gardiner PA, Tremblay MS, Sallis JF: Adults' sedentary behavior determinants and interventions. Am J Prev Med 2011, 41:189-196.

4. Salmon J, Bauman A, Crawford D, Timperio A, Owen N: The association between television viewing and overweight among Australian adults participating in varying levels of leisure-time physical activity. Int J Obes Relat Metab Disord 2000, 24:600-606.

5. Healy GN, Dunstan DW, Salmon J, Cerin E, Shaw JE, Zimmet PZ, Owen N: Objectively measured light-intensity physical activity is independently associated with 2-h plasma glucose. Diabetes Care 2007, 30:1384-1389. 
6. Healy GN, Dunstan DW, Salmon J, Shaw JE, Zimmet PZ, Owen N: Television time and continuous metabolic risk in physically active adults. Med Sci Sports Exerc 2008, 40:639-645.

7. Grøntved A, Hu FB: Television viewing and risk of type 2 diabetes, cardiovascular disease, and all-cause mortality: a meta-analysis. JAMA 2011, 305:2448-2455.

8. Thorp AA, Owen N, Neuhaus M, Dunstan DW: Sedentary behaviors and subsequent health outcomes in adults a systematic review of longitudinal studies, 1996-2011. Am J Prev Med 2011, 41:207-215.

9. Owen N, Healy GN, Matthews CE, Dunstan DW: Too much sitting: the population health science of sedentary behavior. Exerc Sport Sci Rev 2010, 38:105-113.

10. Department of Health, UK: Start Active, Stay Active: A Report on Physical Activity for Health from the Four Home countries' Chief Medical Officers. London: Department of Health; 2011.

11. Bennie JA, Chau JY, van der Ploeg HP, Stamatakis E, Do A, Bauman A: The prevalence and correlates of sitting in European adults - a comparison of 32 Eurobarometer-participating countries. Int J Behav Nutr Phys Act 2013, 10:107.

12. Davis MG, Fox KR, Hillsdon M, Sharp D, Coulson JC, Thompson JL: Objectively measured physical activity in a diverse sample of older urban UK adults. Med Sci Sports Exerc 2011, 43:647-654.

13. Sugiyama T, Salmon J, Dunstan D, Bauman A, Owen N: Neighborhood walkability and TV viewing time among Australian adults. Am J Prev Med 2008, 33:444-449.

14. Healy GN, Matthews CE, Dunstan DW, Winkler EA, Owen N: Sedentary time and cardio-metabolic biomarkers in US adults: NHANES 2003-06. Eur Heart J 2011, 32:590-597.

15. Stamatakis E, Hamer M, Tilling K, Lawlor DA: Sedentary time in relation to cardiometabolic risk factors: differential associations for self-report vs accelerometry in working age adults. Int J Epidemiol 2012, 41:1328-1337.

16. Lader D, Short S, Gershuny J: The Time use Survey, 2005 - how we Spend our Time. 2006.

17. Gardiner PA, Healy GN, Eakin EG, Clark BK, Dunstan DW, Shaw JE, Zimmet $\mathrm{PZ}$, Owen $\mathrm{N}$ : Associations between television viewing time and overall sitting time with the metabolic syndrome in older men and women: the Australian Diabetes Obesity and Lifestyle Study. J Am Geriatr Soc 2011 59:788-796

18. Hamer M, Stamatakis E: Screen-based sedentary behavior, physical activity, and muscle strength in the English Longitudinal Study of Ageing. PLoS One 2013, 8:e66222.

19. Hamer M, Stamatakis E: Prospective study of sedentary behavior, risk of depression, and cognitive impairment. Med Sci Sports Exerc 2014, 46:718-723.

20. Lucas M, Mekary R, Pan A, Mirzaei F, O'Reilly EJ, Willett WC, Koenen K, Okereke Ol, Ascherio A: Relation between clinical depression risk and physical activity and time spent watching television in older women: a 10-year prospective follow-up study. Am J Epidemiol 2011, 174:1017-1027.

21. Sanchez-Villegas A, Ara I, Guillen-Grima F, Bes-Rastrollo M, VaroCenarruzabeitia JJ, Martinez-Gonzalez MA: Physical activity, sedentary index, and mental disorders in the SUN cohort study. Med Sci Sports Exerc 2010, 40:827-834.

22. Trayers T, Lawlor DA, Fox KR, Coulson J, Davis M, Stathi A, Peters T: Associations of objectively measured physical activity with lower limb function in older men and women: Findings from the Older People and Active Living (OPAL) study. J Aging Phys Act 2014, 22:34-43.

23. Withall J, Stathi A, Davis M, Coulson J, Thompson JL, Fox KR: Objective indicators of physical activity and sedentary time and associations with subjective wellbeing in adults aged 70 and over. Int J Environ Res Public Health 2014, 11:643-656.

24. Barnett I, Van Sluiks E, Ogilvie D, Wareham NJ: Changes in household, transport and recreational physical activity and television viewing time across the transition to retirement: longitudinal evidence from the EPIC-Norfolk cohort. J Epidemiol Community Health. in press.

25. Uijtdewilligen L, Twisk JWR, Singh AS, Chinapaw MJM, Van Mechelen W, Brown WJ: Biological, socio-demographic, work and lifestyle determinants of sitting in young adult women: a prospective cohort study. Int J Behav Nutr Phys Act 2014, 11:7.

26. Rhodes RE, Mark RS, Temmel CP: Adult sedentary behavior: a systematic review. Am J Prev Med 2012, 42:e3-e28.
27. Steptoe A, Breeze E, Banks J, Nazroo J: Cohort profile: the English Longitudinal Study of Ageing. Int J Epidemiol 2013, 42:1640-1648.

28. Hamer M, Molloy GJ, De Oliveira C, Demakakos P: Leisure time physical activity, risk of depressive symptoms, and inflammatory mediators: the English Longitudinal Study of Ageing. Psychoneuroendocrinology 2009, 34:1050-1055.

29. Irwin M, Artin $\mathrm{KH}$, Oxman MN: Screening for depression in the older adult: criterion validity of the 10-item Center for Epidemiological Studies Depression Scale (CES-D). Arch Intern Med 1999, 159:1701-1704.

30. Van Der Velde S, Levecque K, Bracke P: Measurement equivalence of the CES-D 8 in the general population in Belgium: a gender perspective. Arch Pub Health 2009, 67:15-29.

31. Katz S, Downs TD, Cash HR: Progress in development of the index of ADL. Gerontologist 1970, 10:20-30.

32. Lawton MP, Brody EM: Assessment of older people: self-maintaining and instrumental activities of daily living. Gerontologist 1969, 9:179-186.

33. Weinstein ND: Misleading tests of health behavior theories. Ann Behav Med 2007, 33:1-10.

34. Van Cauwenberg J, De Donder L, Clarys P, De Bourdeaudhuij I, Owen N, Dury S, De Witte N, Buffel T, Verté D, Deforche B: Relationships of individual, social, and physical environmental factors with older adults' television viewing time. J Aging Phys Act.

35. Kikuchi H, Inoue S, Sugiyama T, Owen N, Oka K, Shimomitsu T: Correlates of prolonged television viewing time in older Japanese men and women. BMC Pub Health 2013, 13:213.

36. Buman MP, Winkler EAH, Kurka JM, Hekler EB, Baldwin CM, Owen N, Ainsworth BE, Healy GN, Gardiner PA: Reallocating time to sleep, sedentary behaviors, or active behaviors: Associations with cardiovascular disease risk biomarkers, NHANES 2005-2006. Am J Epidemiol 2014, 179:323-334.

37. Davis MG, Fox KR, Hillsdon M, Coulson JC, Sharp DJ, Stathi A, Thompson JL: Getting out and about in older adults: the nature of daily trips and their association with objectively assessed physical activity. Int J Behav Nutr Phys Act 2011, 8:116-125.

38. Aoyagi Y, Shephard RJ: Steps per day: the road to senior health? Sports Med 2009, 39:423-438.

39. Salmon J, Owen N, Crawford D, Bauman A, Sallis JF: Physical activity and sedentary behavior: a population-based study of barriers, enjoyment, and preference. Health Psychol 2003, 22:178-188.

40. Buckley JP, Mellor DD, Morris M, Joseph F: Standing-based office work shows encouraging signs of attenuating post-prandial glycaemic excursion. Occup Environ Med 2014, 71:109-111.

41. Dunstan DW, Kingwell BA, Larsen R, Healy GN, Cerin E, Hamilton MT, Shaw JE, Bertovic DA, Zimmet PZ, Salmon J, Owen N: Breaking up prolonged sitting reduces postprandial glucose and insulin responses. Diabetes Care 2010, 35:976-983.

42. Duvivier BMFM, Schaper NC, Bremers MA, Van Crombrugge G, Menheere PPCA, Kars M, Savelberg HH: Minimal intensity physical activity (standing and walking) of longer duration improves insulin action and plasma lipids more than shorter periods of moderate to vigorous exercise (cycling) in sedentary subjects when energy expenditure is comparable. PLoS One 2013, 8:e55542.

43. Steeves JA, Bassett DR, Fitzhugh EC, Raynor HA, Thompson DL: Can sedentary behavior be made more active? A randomized pilot study of TV commercial stepping versus walking. Int J Behav Nutr Phys Act 2012, 9:95.

44. Gardiner PA, Eakin EG, Healy GN, Owen N: Feasibility of reducing older adults' sedentary time. Am J Prev Med 2011, 41:174-177.

45. Rovniak LS, Denlinger L, Duveneck E, Sciamanna CN, Kong L, Freivalds A, Ray CA: Feasibility of using a compact elliptical device to increase energy expenditure during sedentary activities. J Sci Med Sport. in press.

46. Rutten GM, Savelberg HH, Biddle SJH, Kremers SPJ: Interrupting long periods of sitting: good STUFF. Int J Behav Nutr Phys Act 2013, 10:1.

47. Nelson ME, Rejeski WJ, Blair SN, Duncan PW, Judge JO, King AC, Macera CA, Castaneda-Sceppa C: Physical activity and public health in older adults: recommendation from the American College of Sports Medicine and the American Heart Association. Circ 2007, 116:1094-1105.

48. Lally P, Van Jaarsveld CHM, Potts HWW, Wardle J: How are habits formed: modelling habit formation in the real world. Eur J Soc Psychol 2010, 40:998-1009. 
49. Lally P, Gardner B: Promoting habit formation. Health Psychol Rev 2013, 7(Suppl 1):S137-S158.

50. Hamer M, Poole L, Messerli-Bürgy N: Television viewing, C-reactive protein, and depressive symptoms in older adults. Brain Behav Immun 2013, 33:29-32.

51. Wijndaele K, Brage S, Besson H, Khaw K-T, Sharp SJ, Luben R, Wareham NJ, Ekelund U: Television viewing time independently predicts all-cause and cardiovascular mortality: the EPIC Norfolk study. Int J Epidemiol 2011, 40:150-159.

52. Healy GN, Clark BK, Winkler EAH, Gardiner PA, Brown WJ, Matthews CE: Measurement of adults' sedentary time in population-based studies. Am J Prev Med 2011, 41:216-227.

doi:10.1186/s12966-014-0102-3

Cite this article as: Gardner et al: Sociodemographic, behavioural and health factors associated with changes in older adults' TV viewing over 2 years. International Journal of Behavioral Nutrition and Physical Activity 2014 11:102.

\section{Submit your next manuscript to BioMed Central and take full advantage of:}

- Convenient online submission

- Thorough peer review

- No space constraints or color figure charges

- Immediate publication on acceptance

- Inclusion in PubMed, CAS, Scopus and Google Scholar

- Research which is freely available for redistribution 